\title{
On Quality Assurance Mechanisms in Engineering Education: A Case Study of Purdue University
}

\author{
Ming LI, Qing LEI \\ Institute of Higher Education, Beihang University, P.R. China
}

\begin{abstract}
The ABET EC2000 reform has had a range of different impacts on U.S. universities and colleges as they work to meet accreditation standards. This paper uses Purdue University as a case study of these processes. The quality assurance mechanisms in engineering education at Purdue are deeply analyzed and presented based on data from interviews with 10 key stakeholders involved with ABET accreditation at Purdue. All stakeholders were also asked to share their views about other internal quality assurance mechanisms and current efforts to assure the quality of engineering education. The interviews were systematically analyzed using qualitative coding procedures, including inductive and deductive coding. The main data analysis tool was NVIVO 10.0. This paper finds that Purdue, as a research-oriented university, has set up a relatively well-integrated internal quality assurance system of engineering education.
\end{abstract}

KEYWORD: quality assurance; engineering education; ABET; accreditation; EC2000; continuous quality improvement

\section{INTRODUCTION}

In the United States, ABET, Inc. has been recognized the unique authorized accreditor of postsecondary degree-granting programs in engineering. For more than 80 years, accreditation has provided quality control for engineering education in the United States, seeking to assure that graduates of accredited programs are prepared for professional practice. In 2002, ABET, Inc. commissioned the Center for the Study of Higher Education at Pennsylvania State University to undertake a three-and-a-half-year study to assess whether the implementation of the new EC2000 evaluation criteria is having the intended effects [1]. At one single university, especially the researchoriented university like Purdue University with strong quality assurance cultures may pay more attention to setting up internal quality assurance systems at multiple levels. It is assumed that it is necessary to explore how colleges and universities in the United States fully exert their own functions and establish the internal quality assurance mechanisms in order to continuously promote quality improvement.

Research on quality assurance in engineering education mainly relates to engineering education accreditation. Research topics of external quality assurance in higher engineering education are mainly inclusive of organization [1] [2], criteria, process and international comparative research of accreditation system. In the United States, as of 1932 when ECPD promulgated the first engineering accreditation criteria, there are a lot of research literatures related "accreditation criteria" and "accreditation implementation". Particularly since the implementation of EC2000, there are more and more research literatures related "Engineering Criteria 2000" (EC2000), which are inclusive of researches on background, perspective, philosophy, philosophy of EC2000, its impact on U.S. and global engineering education[3][4][5] teaching reforms in colleges and universities, and the educational quality improvement initiatives under the EC2000, etc,. Research papers on teaching reform mainly focused on the reform strategies of engineering teaching and curriculum from the perspective of curriculum design, students appraisal and classroom teaching evaluation under ABET accreditation, and impact of ABET upon the development of engineering disciplines and programs. A few monographs were also produced. Research on quality assurance in engineering education mainly involved internal assurance strategies based on TQM, ISO 9001 and self assessment. In addition, there have some case studies in colleges and universities on how to meet the accreditation [6]. These case studies share the practical experiences of preparing for ABET accreditation. 


\section{RESEARCH METHODS}

\subsection{Research design}

According to the relevance of professionals with this study, and the current situation of engineering education at Purdue, researcher chose the interviewees at Purdue who was responsible for contacting the interviewees. Researcher finally took interview with 10 key stakeholders involved with ABET accreditation at Purdue. The stakeholders were interviewed using a semi-structured protocol which elicited their concrete experiences of preparing for ABET accreditation, as well as their attitudes towards quality assurance in engineering education. As the interview went forward, research issues became continuously more and more complex. In order to improve the particularity and effectiveness of interview, researcher adjusted the interview outline and questions.

\subsection{Data Collection}

Interview adopts face-to-face model. The mediate interview time is about one hour. In order to take an in-depth analysis of interview data, this study transfers all recording transcription into text, and finally forms English text after repeatedly proofreading. Researcher tries to code the interview data in order to ensure the validity of study. Before the start of the interview, researcher repeatedly discussed with advisor and finally made out the scientific interview outline and the interview questions, which provided a good expert validity for this study. In addition, this study uses the multivariate (triangle) test in order to make the study as much as possible to achieve objectiveness and rigorousness, hence enhancing the credibility of the qualitative study. At the same time, this study combines integrated literature review with in-depth interview, compares the conclusion with views widely accepted by academy of engineering education. This study chooses NVIVO 10.0 as data processing tool. NVIVO 10.0 is professional analysis software of qualitative data, and can make in-depth qualitative analysis on the video, audio clips, interviews, documents, photos, media content, and so on[7]. It can help the researcher extract valuable view from the data by encoding, classification, induction and analysis of research content, and record the thinking process for subsequent analysis. This study mainly uses the function of data encoding, data analysis and statistics of NVIVO 10.0, which can analyze the overlapped phenomenon of different views during the interview process based on the theme coding and hierarchical coding of the interview data, further classify the same or similar views to extract valuable information for the research.
In the process of data analysis, the researcher first inputs the transcript of Word format text into NVIVO 10.0, and makes data encoding as for the research question and the interviewees' views. In the process of encoding, this study adopts theme coding and hierarchical coding. First of all, it uses the method of free nodes coding to determine the related topics from the interviewees' views. As the coding process, more and more similar views appear. Then the free nodes are transferred into a tree node, under which related views are classified. It is a clustering process of different views on the same question. The analysis framework of coding also is not completed for one time. As the increase of views and further understanding of researcher to interview data, the tree node and data classification are constantly adjusted. The analysis framework is finally established after the completion of all data coding. The research question which guided this study is how the quality assurance mechanisms in engineering education are established and implemented at undergraduate level at Purdue?

\section{INTERVIEW RESULTS}

\subsection{ABET Accreditation As a Kind of External Quality Assurance Mechanism Is Legitimate and Very Important.}

By 2013, 3278 programs of 671 colleges and universities in the United States have been accredited, which clearly illustrates that "despite the changes and new trends in education, institutions, faculty, and students in the United States see ABET accreditation as the gold standard in technical education accreditation, much as they did 80 years ago" [8]. Within five years, 324 academic programs at 64 institutions in 23 other nations have achieved ABET accreditation. We understand that to manage this growth we need to be more strategic and, next year, will turn our focus to regions where we can make the most impact, such as Latin America and the Middle East. Interviewees universally approve the role and legitimacy of ABET in quality assurance.

\subsection{There Are Also Many Shortcomings Worthy of Introspection although the ABET Accreditation Has Many Advantages}

As the most authoritative professional accreditation organization, the development of ABET is also confronted with challenges and pressure. Its accreditation effectiveness has been much questioned. At the end of the 20th century, ABET accreditation was taken into a controversial environment. As the frequency of accreditation and site visits increases, requires for the legality of accreditation decision increases as well. 
Accreditation criteria became more and more quantitative, rarely relied on the professional judgment. In the early 1990s, ABET acted as a role of "protector" regardless of its good original intention, which gradually became a stumbling block for educational reform. Complaints from engineering education community intensified. Both as engineer and president, President James J. Duderstadt of Michigan University and President Charles M. Vest of MIT stated jointly, engineering education must make significant changes to support the new qualityoriented environment, the rigid and multifarious accreditation criteria seriously hindered the development of engineering educational reform. These concerns received positive response of the Industry Advisory Council and the deans of the large engineering colleges. This revolution eventually led to the EC2000 pilot reform at the end of 20th century. However, over the last decade ABET has been in query. The respondents illustrate their views about ABET by their own participation in accreditation and educational experience. Respondents think accreditation brings a lot of work. In order to meet the demand of ABET, the school requires a large number of human resources, a lot of time, to prepare the information more than the actual material.

\subsection{As of EC2000 reform, there are some changes of quality assurance in engineering education within colleges and universities, but there is no significant change.}

When were asked "since the implementation of EC2000, what major changes do you think about quality assurance in engineering education is?", respondents generally believe that ABET EC2000 reform does not trigger a very significant change. If any, it is very small. P3 believed "Nothing specifically came out directly the result of ABET. We bring the way that ABET happy. But the truth you know, everything we do probably look good we called 'flash classroom', first year engineering has studio, labs, things better going on what's suspect that. Really, the main change that we made as result of EC2000 was adding learning outcome to all the courses and assessing the courses data on individual's learning outcomes, not just overall grade. That is significant change what ABET did."

\subsection{There is no special policy to promote the establishment of quality assurance mechanisms at the college and department level although the concept and principle of "continuous improvement" has been accepted.}

With the in-depth implementation of ABET accreditation, "continuous quality improvement" (CQI) advocated by EC2000 has been deeply rooted in the hearts of the people. When asked "What policies and principles frame the QA system of your department?" respondents mentioned many times and identified the concept of professional accreditation, CQI. However, under the external pressure of accreditation, not everyone agrees with this concept although it has penetrated into people's thought and practice. For instance, P3 believed "CQI is not a new idea. It is a label put on it. Now, they change the focus. It is true. They want mandatory content of curriculum to supposedly to mandatory output of curricula. I'm not sure it truly succeeds like that. They actually still perform, they still pretty much dictate what has to be talked in the curricula, some amount of labs, some amount of science, some general education." In addition, respondents indicate that there is no specific policy to promote the establishment of quality assurance mechanisms. For instance, P2 believed "The policy comes from that the federal government. Saying you need to do. The principle that we basically follow is about "improving students' learning". We do this to improve students' learning. Where we are now, where we should go, are students learning, what we think students should learn to be successful. That is the basically guiding principle." Respondents think that quality assurance depends on active faculty culture, "if professors within the faculty want to reform, they will form a community to complete it". Additionally, the individual effort of pursuing excellence is very important.

\subsection{Quality perceptions of engineering education at Purdue}

Quality perceptions are basic views and opinions of quality, and judgment of subject to the value selection and function realization degree of quality. Its connotation includes two aspects: one is subject's choice of quality value, which embodies on the quality purpose; the other is subject's judgment for the realization degree, which embodies on the subject's judgment for the actual effect. Thus, quality perceptions of engineering education refer to judgment for value selection and function realization degree of their engineering education quality, which embodies on the choice of quality purpose of engineering education, and evaluation and judgment of their own educational quality results. As for Purdue, ABET accreditation in only a kind of quality assurance at minimum level. For instance, P7 believed "ABET originally was set up to ensure the minimum level quality were met. What ABET has done, to a very large stance, is a good thing. They have made sure for every engineering program across the country is looking at important thing, at least to some extent." As a top research university, Purdue makes more efforts in order to demonstrate quality or excellence beyond what is required by 
external quality assurance. As for Purdue's quality of engineering education, respondents universally approve that Purdue has an excellent quality. For instance, P8 believed "Purdue gets good students. Students of engineering are good, are qualified. I think it gets good students, but partly I think the reputation. It has a lot of demands to get engineering education a lot of people. So, Purdue's engineering is a good school, I think it helps to attract the students, and it maintains good high quality students. "

\section{CONCLUSION}

According to the current situation of quality assurance system of higher engineering education in the United States, both external quality assurance from $\mathrm{ABET}$ and internal quality assurance at the level of universities, are expecting change and paradigm transformation. Engineering practice has proved that starting in the 1990s the American engineering education accreditation reform is significant. However, from the perspective of longitudinal development, the impact upon the quality improvement of engineering education is limited.

This paper finds that there exists above phenomenon at even the research-oriented university like Purdue. Programs must assess student performance as part of their accreditation process. The assessment process includes collecting and analyzing the data to support a conclusion. It is essential to demonstrate objectives and outcomes for the program are being measured and accomplished. Programs often struggle with deciding what data to collect and ensuring the data is measurable. At Purdue, programs are certain of the best methods or tools to evaluate the level of achievement of expected outcomes for graduates. Sometimes, the methods seem diversified. Many programs have sailed successfully through previous ABET visits, but they find the newer process of outcomes-based accreditation somewhat overwhelming and do not know how to proceed. In other words, the concept of continuous quality improvement has not been well implemented in the practice of quality assurance. Therefore, there are not systematic and integrated quality assurance mechanisms referring to ABET accreditation. Moreover, it may be proper for us to regard it as a routine self-evaluation mechanisms of coping with ABET accreditation. As many respondents demonstrated, the ABET accreditation represents only a minimum standard, and faculty has various and characteristic approaches coping with it. Compared the external quality assurance mechanism like ABET accreditation, it is more important for the university to establish an integrated internal quality assurance system and mechanisms in a long term.

As a research-oriented university, Purdue has set up a relatively well-integrated internal quality assurance system of engineering education which includes at least two types of mechanisms: organization mechanisms of supporting effective teaching, evaluation mechanisms of teaching and learning. The case of Purdue University represents only one university among many different colleges and universities, it is important for researchers to further explore how quality assurance mechanisms are established in various types of higher learning institutes, both in the U.S. and abroad. Additionally, this paper proposes a basic procedure for gathering data from other relevant stakeholders, including students, faculty, parents and employers. The paper concludes with a discussion of quality assurance approaches and mechanisms in cross-national, comparative perspective, with particular focus on U.S. and Chinese contexts of engineering education.

\section{REFERENCES}

[1] Prados, John W. (eds.) A Proud Legacy of Quality Assurance in the Preparation of Technical Professionals: ABET 75th Anniversary Retrospective. Baltimore: Accreditation Board of Applied Science, Computing, Engineering and Technology (ABET, Inc.), 2007.

[2] Burnet, George and Greich, Janet Rohler. "The Ten Outstanding Engineering Achievements", Centennial Issue: Celebrating One Hundred Years 1893-1993. Engineering Education, January 1994, 83 (1), 3. Peterson, George D. "Engineering Criteria 2000: The ABET Change Version for Change", JOM. New York: Sept 1996, 48, (9), ABT/INFORM Trade and Industry, pp. 1214.

[3] Plados, John W., Peterson, George D., and Lattuca, Lisa R. "Quality Assurance of Engineering Education by Accreditation: The Impact of Engineering Criteria 2000 and Its Globe Influence", Journal of Engineering Education, 2005, (1), 165-184.

[4] ABET. "Sustaining the Change, a Follow-up Report to the Vision for Change", 2004, Accreditation Board for Engineering and Technology, Baltimore, 2004. See also ABET. "Engineering Change: A Study of the Impact of EC2000, Executive Summary" 2006, Accreditation Board for Engineering and Technology, Baltimore, 2006.

[5] Plados, John W., Peterson, George D., and Lattuca, Lisa R. "Quality Assurance of Engineering Education by Accreditation: The Impact of Engineering Criteria 2000 and Its Globe Influence", Journal of Engineering Education, 2005, (1), 175-176.

[6] David F. Ollis et al. Liberal Education in Twenty-First Century Engineering; Responses to ABET/EC 2000 Criteria, Portland: Scitech Book News, 2004, (28).

[7] Miles, M. B. \& Huberman A. M. 2005. Qualitative Data Analysis: An Expanded Sourcebook. 2nd. Ed.

[8] ABET, www.abet.org, 2013. 